\title{
Strong association of HLA BW46 with juvenile onset myasthenia gravis in Hong Kong Chinese
}

\author{
BR HAWKINS, WY CHAN-LUI, ${ }^{*}$ EKK CHOI, AY HO \\ From the Departments of Pathology and (1) Paediatrics, ${ }^{*}$ University of Hong Kong, Hong Kong
}

SUMMARY The HLA antigen distribution and thyroid autoantibody status of 27 Chinese children in Hong Kong with juvenile onset myasthenia gravis have been compared with 110 healthy university students from the same population. Twenty-four of the patients had ocular myasthenia. There was a significantly increased prevalence of HLA BW46 in the patients compared with controls $(67 \%$ vs $26.4 \%, \mathrm{p}<0.005)$ indicating that $\mathrm{BW} 46$ confers a relative risk of 5.6 for juvenile onset myasthenia gravis in Chinese children. The increased prevalence of BW46 was not associated with thyroid autoimmunity in the patients although the antigen is known to be associated with thyrotoxicosis in Chinese. The possibility that BW46 confers protection against the development of acetyl-choline receptor antibodies in Chinese patients is discussed. One patient had the Caucasian antigen B8 and the question whether defective immune response genes were introduced into the Chinese through Caucasian admixture is raised.

The association of myasthenia gravis with the HLA antigen B8 in Caucasians is well established and there is preliminary evidence that this antigen may have some predisposing role for the disease in Thais and Filipinos, ${ }^{1}$ and in Indians. ${ }^{2}$ Other antigens, including HLA B5 and B12, are apparently associated with the disease in Japanese. ${ }^{3}$ A small number of Chinese patients with myasthenia gravis were tested in the 8th International Histocompatibility Workshop ${ }^{4}$ but no definite HLA association with the disease has been reported in this ethnic group.

This report describes a strong association between HLA BW46 and juvenile onset myasthenia gravis in patients of Southern Chinese origin living in Hong Kong.

\section{Materials and methods}

Patients: the sample consisted of 27 myasthenic children (13 boys and 14 girls) followed up for between one and sixteen years by the Department of Paediatrics, University of Hong Kong. All were Southern Chinese in ancestral origin. The diagnosis of myasthenia gravis was based on the undue fatigability of muscles relieved dramatically by

Address for reprint requests: Dr BR Hawkins, Department of Pathology, University of Hong Kong, Queen Mary Hospital Compound, Hong Kong.

Received 21 October 1983. Accepted 2 December 1983 intravenous edrophonium and maintenance anticholinesterase medication, and the exclusion of other neuromuscular disease. The age at onset of first symptoms ranged from 2 to 11 years. Three children had generalised and 24 had ocular myasthenia.

Controls: the control group consisted of 110 undergraduate entrants to the University of Hong Kong, ${ }^{5}$ who were having blood taken as part of their routine medical examinations. No selection process was applied except to ensure that all were of southern Chinese origin.

HLA typing: peripheral blood lymphocytes from patients and controls were tested for a range of HLA A and B antigens by the standard microcytotoxicity test using between 100 and 120 different sera obtained from local donors, through exchange programs, or purchased commercially.

Autoantibodies: antithyroid microsomal (ATM) and antithyroglobulin (ATG) were assayed by passive haemagglutination using Thymune-M and Thymune-T kits (Wellcome Reagents Ltd, Beckenham, UK) in 104 of the control group and in 21 of the patients. ATM and ATG titres were considered to be elevated when agglutination occurred at serum dilutions of $1 / 1600$ and $1 / 80$ respectively.

\section{Results}

The HLA phenotypes, clinical details, and thyroid autoantibody status of 27 patients are shown in table 1. Only patient number 1262 had significantly elevated ATM and ATG titres. This patient was also 
Table 1 HLA phenotypes, autoantibodies and clinical type in 27 juvenile onset myasthentcs

\begin{tabular}{|c|c|c|c|c|c|c|}
\hline Number & $\begin{array}{l}\text { Sex/Age } \\
\text { at onset (yr) }\end{array}$ & $H L A-A$ & $H L A-B$ & $A T G^{*}$ & $A T M^{*}$ & Clinical type \\
\hline $\begin{array}{l}1257 \\
1259 \\
1260 \\
1261 \\
1263 \\
1264 \\
1359 \\
1363 \\
1364 \\
1549 \\
1626 \\
1631 \\
2191 \\
2192 \\
2193 \\
1362 \\
1365 \\
2224 \\
2225 \\
2226 \\
2227 \\
1262 \\
2210 \\
2190 \\
1360 \\
1361 \\
1366\end{array}$ & 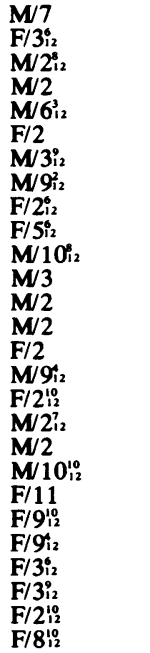 & $\begin{array}{cr}2, \\
2, & 11 \\
2, & 9 \\
& 11 \\
2, & 10 \\
& 11 \\
2 & \\
9, & 19 \\
3, & 9 \\
10, & 11 \\
2, & 11 \\
9, & 11 \\
2, & 11 \\
2 & \\
2, & 11 \\
2, & 11 \\
2, & 11 \\
2, & 19 \\
2 & \\
11, & 19 \\
9, & 11 \\
2, & 11 \\
2 & \\
& 11 \\
2, & 11 \\
2, & 11\end{array}$ & $\begin{array}{r}40 \\
38,46 \\
46 \\
5,40 \\
8,46 \\
35,40 \\
46 \\
22,40 \\
35,40 \\
15,46 \\
13,46 \\
5,46 \\
46 \\
46 \\
35 \\
40,46 \\
15,46 \\
12,46 \\
46 \\
17,15 \\
15,46 \\
13,22 \\
46 \\
63,46 \\
40,46 \\
15,46 \\
15\end{array}$ & $\begin{array}{l}- \\
- \\
- \\
- \\
- \\
- \\
- \\
- \\
- \\
- \\
- \\
- \\
- \\
- \\
- \\
-\end{array}$ & $\begin{array}{l}200 \\
- \\
- \\
- \\
- \\
- \\
400 \\
- \\
- \\
- \\
- \\
- \\
1600 \\
400 \\
800 \\
- \\
-\end{array}$ & $\begin{array}{l}\text { ocular } \\
\text { ocular } \\
\text { ocular } \\
\text { ocular } \\
\text { ocular } \\
\text { ocular } \\
\text { ocular } \\
\text { ocular } \\
\text { ocular } \\
\text { ocular } \\
\text { ocular } \\
\text { ocular } \\
\text { ocular } \\
\text { ocular } \\
\text { ocular } \\
\text { ocular } \\
\text { ocular } \\
\text { ocular } \\
\text { ocular } \\
\text { ocular } \\
\text { ocular } \\
\text { ocular + thyrotoxicosis } \\
\text { ocular + thyrotoxicosis } \\
\text { ocular + dystonia } \\
\text { generalized } \\
\text { generalized } \\
\text { generalized }\end{array}$ \\
\hline
\end{tabular}

*-indicates ATG titre $\leqslant 1 / 10$ or ATM $\leqslant 1 / 100$

known to have thyrotoxicosis. Four of the other patients, including one with thyrotoxicosis, had slight but diagnostically insignificant elevations in ATM titre. None of the normal controls gave an ATM titre higher than $1 / 100$ or an ATG titre higher than $1 / 10$. A comparison of the HLA antigen frequencies in the patients and controls is shown in table 2.

The most striking difference between the patients and controls in table 2 is the high frequency of

Table 2 HLA antigen frequencies in patients and controls

\begin{tabular}{|c|c|c|c|}
\hline & \multicolumn{2}{|c|}{ Patients $(n=27)$} & \multirow{2}{*}{$\frac{\text { Controls }(n=110)}{\%}$} \\
\hline & Observed & $\%$ & \\
\hline A1 & - & & 1.8 \\
\hline A2 & 15 & 56 & 56.4 \\
\hline $\begin{array}{l}\text { A3 } \\
\text { A9 }\end{array}$ & 1 & 4 & $\begin{array}{r}0.9 \\
23.6\end{array}$ \\
\hline $\begin{array}{l}\text { A9 } \\
\text { A10 }\end{array}$ & $\begin{array}{l}5 \\
2\end{array}$ & $\begin{array}{r}19 \\
7\end{array}$ & $\begin{array}{r}23.6 \\
3.6\end{array}$ \\
\hline A11 & 17 & 63 & $48 \cdot 2$ \\
\hline AW19 & 3 & 11 & $17 \cdot 3$ \\
\hline $\begin{array}{l}\text { B5 } \\
\text { B15 }\end{array}$ & 2 & 7 & $9 \cdot 1$ \\
\hline BW35 & $\begin{array}{l}7 \\
3\end{array}$ & $\begin{array}{l}26 \\
11\end{array}$ & $\begin{array}{r}13.6 \\
6.4\end{array}$ \\
\hline & - & & $5 \cdot 4$ \\
\hline B8 & 1 & 4 & $0 \cdot 9$ \\
\hline $\begin{array}{l}\text { B12 } \\
\text { B13 }\end{array}$ & $\begin{array}{l}1 \\
2\end{array}$ & $\begin{array}{l}4 \\
7\end{array}$ & $\begin{array}{r}2.7 \\
10.9\end{array}$ \\
\hline BW16 & 1 & 4 & 7.2 \\
\hline B17 & 1 & 4 & 22.7 \\
\hline BW22 & 2 & 7 & $7 \cdot 3$ \\
\hline B40 & 7 & $\overline{26}$ & 32.7 \\
\hline BW46 & 18 & 67 & $26 \cdot 4$ \\
\hline
\end{tabular}

*includes BW63
BW46 and the low frequency of B17 in the patients. Based on the data in table 2 the relative risk for juvenile onset myasthenia gravis conferred by HLA BW46 is $5.6\left(\chi^{2}=13.87\right.$ with Yates' correction). Even after multiplying the associated probability value by 20 to take account of the number of antigens tested, the probability of such a difference between patients and controls occurring by chance is < $0.005\left(\right.$ Hawkins $\left.^{6}\right)$. Moreover, table 1 shows that of the nine patients without BW46, six had antigens of the B5/B15/BW35 cross-reactive group which apparently includes BW46 (unpublished data) and which have been reported to have weak associations with myasthenia gravis in non-Caucasians. ${ }^{23}$ Interestingly, one patient had both BW46 and B8, the latter being rare in Orientals but associated with myasthenia gravis in Caucasians.

\section{Discussion}

The association of myasthenia gravis with the HLA system has been known for over a decade following the initial report of an elevated frequency of HLA B8 in Finnish patients. ${ }^{7}$ The accumulated evidence in Caucasians has confirmed without doubt that the increased frequency of HLA B8 relates to adultonset myasthenia gravis, particularly in females with early onset disease and with thymic hyperplasia rather than thymoma. In Japanese patients it is probable that HLA B12 predisposes to the disease in the same way as B8 in Caucasians. ${ }^{3} \mathrm{~A}$ small 
number of Chinese patients with myasthenia gravis and controls were HLA-typed in the 8th International Histocompatibility Workshop but the results were unsatisfactory owing to the absence of antisera detecting the important Oriental antigen BW46. ${ }^{4}$ No association between HLA antigens and myasthenia gravis has previously been reported in this ethnic group.

In almost all the patients studied to date the predominant disease type has been generalised rather than ocular myasthenia gravis. Hitherto, no HLA association has been found with ocular myasthenia gravis (Christiansen et al, cited in Garlepp et al ${ }^{8}$ ). The present finding in Chinese children, therefore, is particularly important. Firstly the finding shows a strong association between HLA BW46 and juvenile onset myasthenia gravis, and secondly it questions whether the association is primarily with juvenile onset disease per se or with ocular myasthenia gravis with which most patients were affected.

Previous studies have shown an increased prevalence of associated thyroid autoantibodies with or without florid thyroid disease in patients with ocular myasthenia gravis. ${ }^{9}$ It is of interest, therefore, that BW46, the antigen associated with juvenile onset myasthenia gravis in this study, is known to be associated with thyrotoxicosis in Chinese. ${ }^{10}$ However, in the present study there was no excess of thyroid autoantibodies in the patients and only two patients had clinically apparent thyrotoxicosis. This suggests that the high prevalence of BW46 in this study is not secondary to an association with thryoid autoimmunity.

Preliminary findings in adult myasthenic patients in Hong Kong suggest an increased prevalence of HLA BW46 in patients without acetyl-choline receptor antibody (unpublished data). Therefore, since most of the patients in the present study had ocular myasthenia gravis in which acetyl-choline receptor antibody is known to occur comparatively rarely, ${ }^{8}$ it is attractive to consider whether HLA BW46 confers some protection against the development of acetyl-choline receptor antibody in Chinese myasthenic patients. Further studies are in progress to test this hypothesis. However, a precedent for the involvement of the HLA system in determining the clinical course of myasthenia gravis is known in Caucasian patients in whom HLA B8 occurs more frequently in adult females with early onset disease without thymoma. In this regard the finding in the present study that one patient had both HLA BW46 and HLA B8 was of particular interest. HLA B8 is rare in Orientals but is strongly associated with autoimmune disease including myasthenia gravis in Caucasians. In the 2nd Asia and
Oceania Histocompatibility Workshop, three Thai patients and one Filipino patient with myasthenia gravis were found to have HLA B8 although the antigen was not present in the normal control samples of these ethnic groups.' B8 has also been found to be associated with myasthenia gravis in India. ${ }^{2}$ In the normal control group of 110 healthy university students in the present study only one had HLA B8 although in Chinese hospital patients in Hong Kong the antigen has been found in patients with adultonset myasthenia gravis, Graves' disease, and systemic lupus erythematosus. These findings suggest that even though the immune response genes associated with HLA B8 in Caucasians are apparently associated with different HLA alleles in nonCaucasians, these same response genes remain associated with HLA B8 in non-Caucasian populations. HLA B8 was almost certainly introduced into the Chinese gene pool through Caucasian admixture. Whether or not the defective immune response genes associated with autoimmune disease in Chinese were introduced at the same time poses an interesting anthropological question.

\section{References}

' Garlepp MJ, Christiansen FT, Chiewsilp P, Dawkins RL. Myasthenia Gravis. In: Simons MJ, Tait BD, eds. Proceedings of the Second Asia and Oceania Histocompatibility Workshop Conference. Melbourne: Immunopublishing, 1983;343-7.

${ }^{2}$ Mehra MK, Ahuja GK, Taneja V, Vaidya MC. HLA antigens and myasthenia gravis in north India. $J$ Neurol Neurosurg Psychiatry 1983;46:361-4.

${ }^{3}$ Yoshida $T$, Tsuchiya $M$, Ono A, Yoshimatsu $H$, Satoyoshi E, Tsuji, K. HLA antigens and myasthenia gravis in Japan. J Neurol Sci 1977;32:195-201.

${ }^{4}$ Dawkins R. Myasthenia Gravis. In: Terasaki PI, ed. Histocompatibility Testing 1980. Los Angeles: UCLA Tissue Typing Laboratory, 1980;662-7.

${ }^{5}$ Hawkins BR, Ho A, Choi EKK, Osmund IF. HLA A antigens, Glyoxalase $I$ and Esterase $D$ markers in Hong Kong Chinese: Hum Genet 1984 (in press).

${ }^{6}$ Hawkins BR. Table of critical chi-square values for investigations involving multiple comparisons. Tissue Antigens 1981;17:243-4.

' Pirskanen R, Tiilikainen A, Hokkanen E. Histocompatibility (HL-A) antigens associated with myasthenia gravis. Ann Clin Res 1972;4:304-6.

${ }^{8}$ Garlepp MJ, Dawkins RL, Christiansen FT, et al. Autoimmunity in ocular and generalised myasthenia gravis. J Neuroimmunol 1981;1:325-32.

' Dawkins RL, Christiansen FT, Garlepp MJ. Autoantibodies and HLA antigens in ocular, generalized and penicillamine-induced myasthenia gravis. Ann NY Acad Sci 1981;377:372-84.

${ }^{10}$ Chan SH, Yeo PPB, Lui KF, et al. HLA and thyrotoxicosis (Graves' Disease) in Chinese. Tissue Antigens 1978;12:109-14. 